Provided for non-commercial research and education use. Not for reproduction, distribution or commercial use.

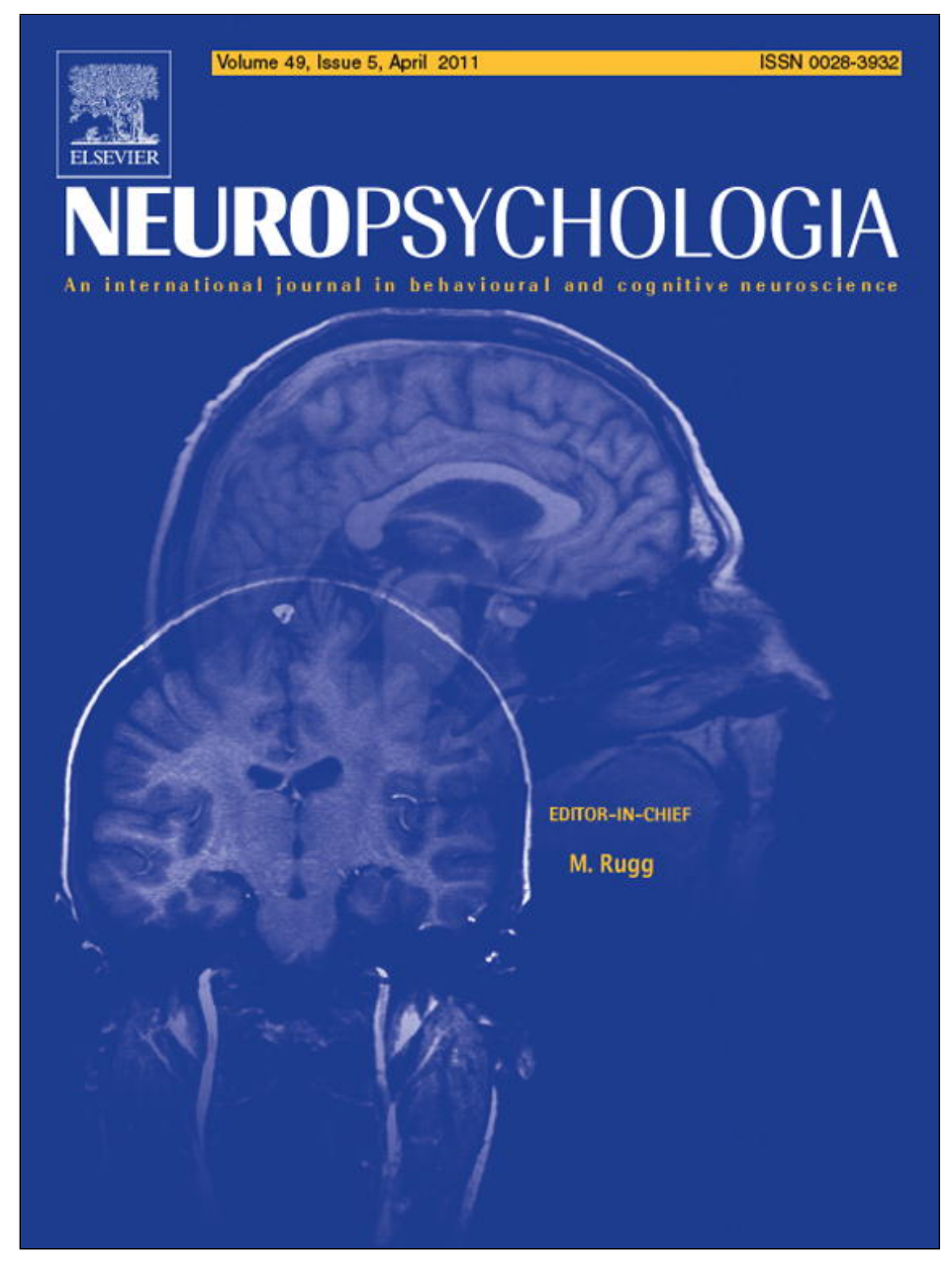

This article appeared in a journal published by Elsevier. The attached copy is furnished to the author for internal non-commercial research and education use, including for instruction at the authors institution and sharing with colleagues.

Other uses, including reproduction and distribution, or selling or licensing copies, or posting to personal, institutional or third party websites are prohibited.

In most cases authors are permitted to post their version of the article (e.g. in Word or Tex form) to their personal website or institutional repository. Authors requiring further information regarding Elsevier's archiving and manuscript policies are encouraged to visit:

http://www.elsevier.com/copyright 


\title{
Phonological learning in semantic dementia
}

\author{
Elizabeth Jefferies ${ }^{\mathrm{a}, *}$, Samantha Bott ${ }^{\mathrm{a}}$, Sheeba Ehsan ${ }^{\mathrm{b}}$, Matthew A. Lambon Ralph ${ }^{\mathrm{b}}$ \\ a University of York, UK \\ ${ }^{\mathrm{b}}$ University of Manchester, UK
}

\section{A R T I C L E I N F O}

\section{Article history:}

Received 20 September 2010

Received in revised form 13 January 2011

Accepted 20 January 2011

Available online 26 January 2011

\section{Keywords:}

Semantic dementia

Word learning

Phonology

Semantic memory

Anterior temporal lobe

\begin{abstract}
A B S T R A C T
Patients with semantic dementia (SD) have anterior temporal lobe (ATL) atrophy that gives rise to a highly selective deterioration of semantic knowledge. Despite pronounced anomia and poor comprehension of words and pictures, SD patients have well-formed, fluent speech and normal digit span. Given the intimate connection between phonological STM and word learning revealed by both neuropsychological and developmental studies, SD patients might be expected to show good acquisition of new phonological forms, even though their ability to map these onto meanings is impaired. In contradiction of these predictions, a limited amount of previous research has found poor learning of new phonological forms in SD. In a series of experiments, we examined whether SD patient, GE, could learn novel phonological sequences and, if so, under which circumstances. GE showed normal benefits of phonological knowledge in STM (i.e., normal phonotactic frequency and phonological similarity effects) but reduced support from semantic memory (i.e., poor immediate serial recall for semantically degraded words, characterised by frequent item errors). Next, we demonstrated normal learning of serial order information for repeated lists of single-digit number words using the Hebb paradigm: these items were well-understood allowing them to be repeated without frequent item errors. In contrast, patient GE showed little learning of nonsense syllable sequences using the same Hebb paradigm. Detailed analysis revealed that both GE and the controls showed a tendency to learn their own errors as opposed to the target items. Finally, we showed normal learning of phonological sequences for GE when he was prevented from repeating his errors. These findings confirm that the ATL atrophy in SD disrupts phonological processing for semantically degraded words but leaves the phonological architecture intact. Consequently, when item errors are minimised, phonological STM can support the acquisition of new phoneme sequences in patients with SD.
\end{abstract}

(c) 2011 Elsevier Ltd. All rights reserved.

\section{Introduction}

Semantic dementia (SD) is the temporal variant of frontal-temporal dementia, and is associated with progressive bilateral atrophy and hypometabolism focussed on the anterior infero-temporal neocortex (Chan et al., 2001; Mummery et al., 2000; Nestor, Fryer, \& Hodges, 2006). Patients with SD show a highly uniform, progressive and selective disorder of semantic memory: in a full range of semantic tasks - including picture naming, verbal and non-verbal comprehension - they show gradual degradation of the structure of conceptual knowledge, which first affects fine-grained distinctions between similar entities (e.g., breeds of dog) and later erodes more basic semantic knowledge (e.g., dogs vs. other animals; Bozeat, Lambon Ralph, Patterson, Garrard, \& Hodges, 2000; Lambon Ralph \& Patterson, 2008; Rogers

\footnotetext{
* Corresponding author at: Department of Psychology, University of York, York Y010 5DD, UK. Tel.: +4401904 434368

E-mail address: ej514@york.ac.uk (E. Jefferies).
}

et al., 2004). In contrast, their perceptual and spatial skills, new episodic learning, non-verbal reasoning, syntax and phonology remain largely intact, at least until the later stages of the disease (Hodges, Patterson, Oxbury, \& Funnell, 1992; Snowden, Neary, \& Mann, 1996). This highly selective nature of the disorder allows researchers to explore the impact of semantic degradation on language tasks that are not necessarily thought to involve semantic access, such as reading, spelling, past-tense generation and verbal short-term memory (STM) (e.g., Jefferies, Jones, Bateman, \& Lambon Ralph, 2004; Patterson, Graham, \& Hodges, 1994; Patterson \& Hodges, 1992; Patterson et al., 2006).

The status of phonological processing in SD is of particular relevance to investigations of language and verbal STM. Patients with SD produce fluent speech which is largely free from phonological errors but which can be relatively empty and/or include semantic jargon (Kertesz, Jesso, Harciarek, Blair, \& McMonagle, 2010). SD patients also perform relatively well on explicit phonological judgement tasks like minimal pairs (detecting that two phonologically similar words - e.g., cup/cut - are different), phoneme segmentation tasks (requiring phonemes to be added 
to or deleted from words) and rhyme generation, although more severely impaired cases can show mild impairment (Jefferies, Jones, Bateman, \& Lambon Ralph, 2005; Knott, Patterson, \& Hodges, 1997; Knott, Patterson, \& Hodges, 2000). SD patients have excellent phonological STM: they have normal digit span (Jefferies, Patterson, Jones, Bateman, \& Lambon Ralph, 2004) and normal or near-normal immediate serial recall (ISR) for nonwords (Jefferies et al., 2005; Majerus, Norris, \& Patterson, 2007). They exhibit standard effects of phonological similarity in ISR - i.e., poorer recall of phonologically confusable letters such as $\mathrm{G}, \mathrm{T}, \mathrm{B}, \mathrm{V}$, and $\mathrm{P}$, as opposed to more distinct-sounding items, such as J, M, O, C, and R (Jefferies et al., 2005; Knott et al., 2000; Majerus et al., 2007; McCarthy \& Warrington, 2001), suggesting that their verbal STM relies heavily on a phonological code, as it does in healthy individuals (Baddeley, 1966; Conrad, 1964; Conrad \& Hull, 1964). Finally, several SD cases have shown pronounced effects of phonotactic frequency in nonword recall, i.e., better recall of nonwords comprising phoneme pairs that are common in the language (Majerus et al., 2007). This suggests that their verbal STM is supported by long-term phonological knowledge in the normal way.

Despite their good phonological and serial order abilities, patients with SD make frequent phoneme order errors when attempting to repeat sequences of words they no longer fully understand and consequently their word span is severely impaired. Phonemes typically migrate to the same syllable position in a neighbouring word, for example, "mint, rug" might be recalled as "rint, mug" (Hoffman, Jefferies, Eshan, Jones, \& Lambon Ralph, 2009; Patterson et al., 1994). This phonological breakdown is more severe for words that are poorly understood as opposed to items that are still comprehended relatively well (according to performance on semantic tests such as picture naming and word-picture matching), even when the frequency of words in the two sets is matched (Jefferies, Jones, et al., 2004; Jefferies et al., 2005; Jefferies, Patterson, et al., 2004; Knott et al., 1997; Knott et al., 2000; Majerus et al., 2007). This suggests that semantic knowledge contributes directly to the stability of phonological information in STM. Moreover, the excellent digit span abilities of SD patients may similarly follow from the fact that the magnitude-meaning of numbers relies on parietal areas spared by the anterior temporal atrophy - consequently, number words continue to receive semantic support in ISR (Cappelletti, Kopelman, \& Butterworth, 2002; Jefferies, Patterson, et al., 2004). Healthy participants produce phoneme migrations in ISR similar to those seen in SD when repeating sequences of nonwords that lack support from lexical/semantic knowledge but such errors are rare in word recall (e.g., Hoffman et al., 2009; Jefferies, Frankish, \& Lambon Ralph, 2006).

This strong association between the availability of semantic information and phonological disintegration suggests that semantic knowledge contributes to phoneme binding processes that allow the phonological elements of words to emerge together in the correct configuration in speech output. The contribution of word meaning to phonological stability is likely to be especially prominent in tasks like ISR that require the maintenance of multiple items (Jefferies et al., 2006; Patterson et al., 1994). According to Patterson et al. (1994), two sources of constraint on phoneme binding emerge from the interplay of phonology and semantics underpinning verbal STM and language production more generally. First, the phonological system itself produces stronger patterns of activation for familiar sequences of phonemes - this gives rise to phonotactic frequency effects and contributes to better recall of words compared with nonwords. Secondly, every time a word is spoken or comprehended, semantic activation co-occurs with phonological activation. Consequently, activation within the semantic system provides another constraint on phonological coherence (referred to as "semantic binding"; see also Jefferies et al., 2006). The phoneme migration errors in ISR observed in patients with SD reflect a reduction in this second constraint.

In summary, patients with SD show reduced semantic binding within the phonological system but largely normal phonological processing for meaningless items and when semantic activation is still possible (i.e., for number words and other preserved concepts). Given this neuropsychological profile, we might expect SD patients to show good learning of new phonological forms, even if they cannot be readily associated with meanings. There is ample evidence - both from developmental and neuropsychological studies - suggesting that the capacity to maintain a novel string of phonemes in STM underpins long-term learning of new words (for reviews, see Baddeley, Gathercole, \& Papagno, 1998; Gupta \& Tisdale, 2009). Gathercole, Baddeley and colleagues have repeatedly demonstrated that nonword repetition correlates with vocabulary size in young children, in both cross-sectional and longitudinal studies: for example, phonological STM capacity at 4 years of age predicts vocabulary size a year later, even when vocabulary scores at age 4 are taken into account (Gathercole \& Baddeley, 1989; Gathercole, Hitch, Service, \& Martin, 1997; Gathercole, Willis, Emslie, \& Baddeley, 1992). Recent work has shown that children's ability to learn a digit sequence in the Hebb paradigm is related to nonword learning but not paired-associate learning (Mosse \& Jarrold, 2008). The Hebb paradigm taps incidental learning of verbal serial order information: participants show superior ISR for repeated as opposed to non-repeated digit sequences, even when they are unaware that any lists were repeated. Longitudinal studies have also found that serial order aspects of STM are particularly critical for vocabulary acquisition in children (as opposed to other phonological skills; Leclercq \& Majerus, 2010).

The same relationships between phonological STM/serial order capacity and new word learning exist in adults: individuals who are better at retaining sequences of phonemes are better at acquiring new items of vocabulary (Gupta, 2003; Majerus, Poncelet, Van der Linden, \& Weekes, 2008). Szmalec, Duyck, Vandierendonck, Mata, and Page (2009) presented sequences of syllables in a Hebb learning paradigm and found better recall of repeated sequences that had become familiar nonwords in healthy adults, leading the authors to argue that the Hebb paradigm is a laboratory analogue of naturalistic word learning. In addition, stroke patients with specific deficits in phonological STM show severe impairment when asked to learn new words. For example, patient PV was able to learn associations between familiar words but was completely unable to acquire links between familiar words and foreign vocabulary (Baddeley, Papagno, \& Vallar, 1988), indicating that the retention of novel sequences of phonemes plays a fundamental role in vocabulary acquisition.

In contrast to phonological STM cases, patients with SD might be expected to display good learning of novel phoneme sequences (due to their excellent phonological STM and serial order skills) yet impaired acquisition of new meanings. However, there is limited and contradictory research on this topic. Several studies have found that patients with SD can relearn the names of real objects and retain these gains over a month or more, especially when they still possess some semantic or personal knowledge of the trained items (Green Heredia, Sage, Lambon Ralph, \& Berthier, 2008; Jokel, Rochon, \& Anderson, 2010; Jokel, Rochon, \& Leonard, 2006; Snowden \& Neary, 2002); however, other research has reported less success (Graham, Patterson, Pratt, \& Hodges, 2001; Henry, Beeson, \& Rapcsak, 2008). Moreover, as all of these studies required patients to learn both semantic and phonological information, they did not examine whether SD cases can learn novel phonological sequences presented in isolation. Only one study to our knowledge has specifically examined the acquisition of new phonological forms in SD. Using a closed set of nonwords in an ISR task, Majerus et al. (2007) examined whether two SD patients could learn the phonological 
forms of meaningless items when they were presented in different orders over a short block of trials. Healthy controls showed some learning of the items (as evidenced by improved performance over the block of trials) but the SD participants did not - even though they demonstrated normal serial order learning for digit sequences using the Hebb paradigm (see Reilly, Martin \& Grossman, 2005, for a similar study involving repetition of a closed set of words in ISR).

Our study aimed to resolve this puzzle by investigating the circumstances in which SD patient GE was able to learn new phoneme sequences. In the first section, we verified that GE showed the expected pattern of preserved phonological yet degraded semantic contributions to verbal STM. We contrasted ISR for (i) 'known' and 'semantically degraded' words (according to picture naming performance) and (ii) word and nonword recall. This established whether GE displayed normal ISR for nonwords, yet phoneme migrations for semantically degraded words (like previous SD cases). We also examined the effect of phonotactic frequency on ISR for nonwords, to determine whether long-term phonological knowledge at the sublexical level continues to support verbal STM in SD. Experiments 1-4 addressed the more novel question of whether GE could learn new phonological sequences. Experiment 1 provides a starting point by replicating the nonword learning study of Majerus et al. (2007) - GE, like the two previously reported patients, was unable to demonstrate phonological learning in this paradigm. Experiments 2 and 3 explored whether GE could learn new sequences of known items (digits) and CV nonwords using the Hebb paradigm. Experiment 4 employed an error-reducing paradigm to teach GE nonwords. These experiments together established whether phonological learning could occur at a normal rate in patient GE.

\section{Participants}

Patient GE was a 51-year old man, who left school aged 16 . At the time of the study, he had shown a selective yet worsening deficit in semantic memory for about four years. An MRI scan revealed bilateral anterior temporal atrophy that was more marked in the left hemisphere (Fig. 1). GE showed substantial impairment on a wide range of semantic tasks employing different input and output modalities, including picture naming, word-picture matching and judgements of semantic association for pictures and words (see Table 1). In contrast, he performed within normal limits on non-semantic tests, including components of the Visual Object and Space Perception battery (VOSP; Warrington \& James, 1991) and the Raven's Coloured Progressive Matrices test of non-verbal reasoning (Raven, 1962). His speech was fluent and without phonological errors, although characterised by word-finding difficulties (see Appendix A for his description of the 'cookie theft' picture, Goodglass \& Kaplan, 1983). His digit span was normal and he performed relatively well on explicit phonological judgement tasks (see Table 1). In line with other SD patients, he also showed a substantial effect of phonological similarity on letter recall (see Table 1; Jefferies et al., 2005).

In our experimental tasks, GE was compared with eight healthy control participants aged $51-61$ ( mean $=57$ years), who left formal education between the ages of 15 and 18 . There were four females and four males.

\section{Methods across experiments}

\subsection{Procedure for immediate serial recall experiments}

Items for ISR were spoken by the experimenter at a rate of one per second. Participants attempted to recall the items immediately in serial order. Responses were audio recorded for later transcription. Each response was coded as either correct, an order error (i.e., a target item in the wrong position in the sequence) or an item error (not a target item). When participants produced fewer responses than the number of items in the sequence, omissions were positioned to maximise the number of

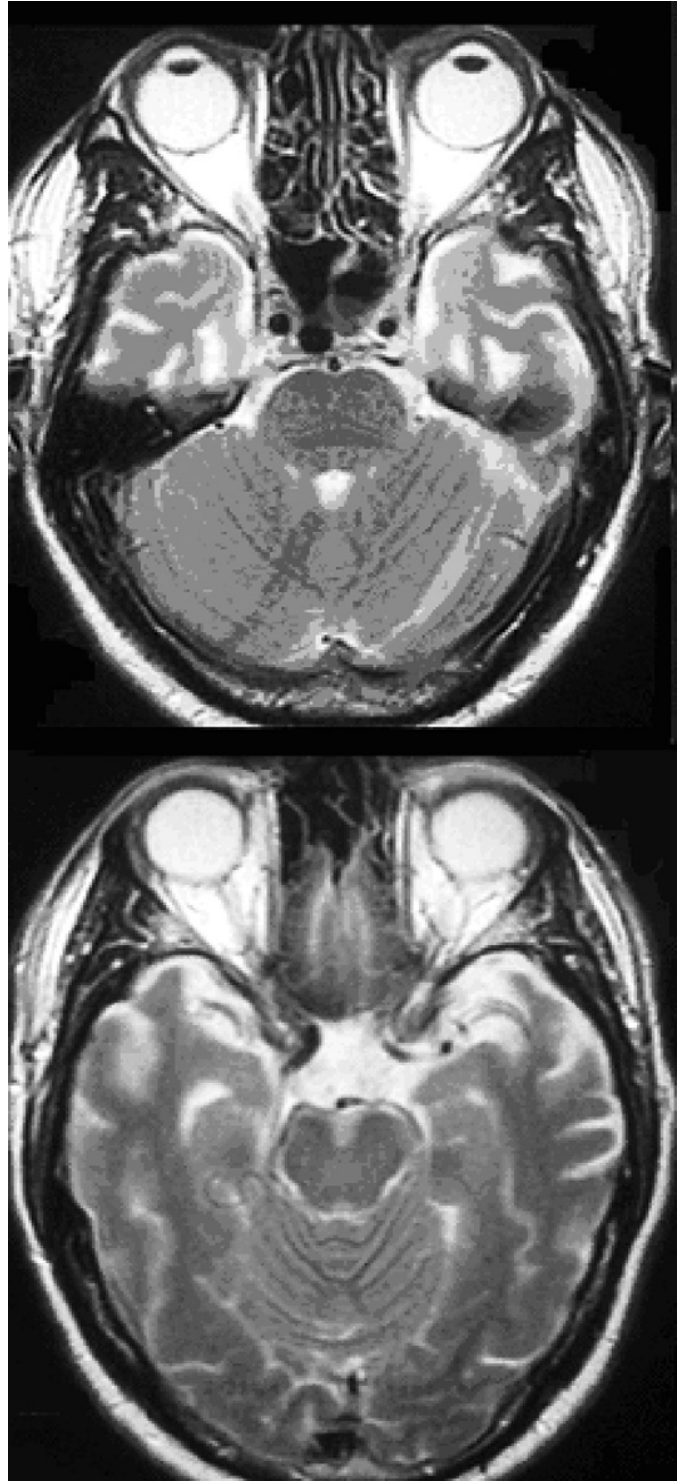

Fig. 1. MRI of patient GE.

items scored as correct (for example, the sequence 8, 1, 4, 6, 2 recalled as " $8,4,6,2$ " would be transcribed as 8 , blank, $4,6,2$, rather than treating the final three items as order errors).

\subsection{Statistical analysis}

We used independent $t$-tests (or ANOVA for factorial designs) to examine the influence of experimental manipulations on GE's ISR accuracy (i.e., the number of items recalled in the correct sequence per list), treating lists as cases. We used the "singlims" procedure (Crawford \& Garthwaite, 2002) to determine the extent to which GE was impaired in each condition: this method uses a modified $t$-statistic to examine whether an individual is significantly below control performance, taking into account variation and sample size for the control group. We also used the Revised Standardised Difference Test (RSDT; Crawford \& Garthwaite, 2005), which uses modified $t$-tests to establish whether the difference between two experimental conditions or tasks is significantly greater/smaller for a patient than controls. This method expresses performance on the two conditions as standardised scores and takes into account the size of the control sample and the correlation between the two measures being compared. All $p$ values are one-tailed unless otherwise stated.

\section{Influences of semantic and phonological knowledge on ISR}

To establish whether GE showed relatively normal STM for phonological information but impaired semantic support for ISR, 
Table 1

Neuropsychological test scores.

\begin{tabular}{|c|c|c|c|c|c|}
\hline & & \multirow[t]{2}{*}{ Max. } & \multirow[t]{2}{*}{ GE } & \multicolumn{2}{|c|}{ Controls } \\
\hline & & & & $M$ & s.d. \\
\hline \multirow[t]{5}{*}{ Semantic } & Picture naming & 64 & $13^{\mathrm{a}}$ & 62.3 & 1.6 \\
\hline & Word-picture matching & 64 & $32^{\mathrm{a}}$ & 63.7 & 0.5 \\
\hline & Pyramids and Palm Trees: Pictures & 52 & $35^{\mathrm{a}}$ & 51.2 & 1.4 \\
\hline & Pyramids and Palm Trees: Words & 52 & $34^{\mathrm{a}}$ & 51.1 & 1.1 \\
\hline & Synonym judgement & 96 & $63^{\mathrm{a}}$ & 93.1 & 2.5 \\
\hline \multirow[t]{12}{*}{ Phonological/STM } & PALPA 9: Word repetition & 80 & 78 & 78.8 & 1.4 \\
\hline & PALPA 8: Nonword repetition & 30 & 29 & NA & \\
\hline & Digit span: Forwards & - & 7 & 6.8 & 0.9 \\
\hline & Digit span: Backwards & - & 4 & 4.7 & 1.2 \\
\hline & PALPA 2: Minimal pairs - words & 72 & 72 & 70.4 & 2.7 \\
\hline & PALPA 1: Minimal pairs - nonwords & 72 & 65 & 70.8 & 2.4 \\
\hline & Phoneme segmentation: Addition & 48 & 44 & NA & \\
\hline & Phoneme segmentation: Deletion & 48 & 43 & NA & \\
\hline & Rhyme judgement & 48 & 47 & NA & \\
\hline & Rhyme production & 24 & 24 & NA & \\
\hline & ISR: Phonologically distinct letters & 40 & 40 & 38.6 & 1.8 \\
\hline & ISR: Phonologically similar letters & 40 & 27 & 33.1 & 3.8 \\
\hline \multirow[t]{6}{*}{ Visual/executive } & VOSP: Dot counting & 10 & 10 & NA & \\
\hline & VOSP: Position discrimination & 20 & 20 & NA & \\
\hline & VOSP: Number location & 10 & 9 & NA & \\
\hline & VOSP: Cube analysis & 10 & 10 & NA & \\
\hline & Rey figure immediate copy & 36 & 35 & 34.0 & 2.9 \\
\hline & Coloured Progressive Matrices & 36 & 33 & NA & - \\
\hline
\end{tabular}

a Impaired performance. NA: not available. Max: maximum score. Naming and word-picture matching from Bozeat et al. (2000). Pyramids and Palm Trees test of semantic association from Howard and Patterson (1992). Synonym judgement from Jefferies, Patterson, Jones, and Lambon Ralph (2009). PALPA: Psycholinguistic Assessments of Language Processing in Aphasia (Kay, Lesser, \& Coltheart, 1992). Phoneme segmentation and rhyme judgement/production tasks from Patterson and Marcel (1992). ISR for phonologically distinct and similar letters from Jefferies et al. (2005) - involved ISR for four-letter lists (e.g., R, J, F, L vs. D, P, B, E). VOSP: Visual Object and Space Perception battery (Warrington \& James, 1991). Non-verbal reasoning assessed using Coloured Progressive Matrices test (Raven, 1962).

we examined his recall of nonwords and words classified as wellunderstood or more semantically degraded. We also examined retention of nonwords sequences with high or low phonotactic frequency (i.e., phoneme combinations that occur commonly or rarely in English). Majerus et al. (2007) found that two SD patients showed a normal influence of phonotactic frequency on nonword ISR, suggesting that although the contribution of semantic knowledge to verbal STM is greatly eroded, phonological knowledge continues to support ISR in a normal way.

\subsection{ISR for known and degraded words and nonwords}

\subsubsection{Method}

Words were categorized as 'known' or 'semantically degraded' using picture naming: 'known' words were named correctly by GE on two separate occasions, while 'degraded' words were named incorrectly both times. These word sets, containing twenty items each, were matched for frequency and syllable length. Nonwords were generated from the 'known' and 'degraded' words by replacing the first phoneme. GE was presented with word lists containing 3-5 items, while controls were tested on 4-6 words per trial. For the nonwords, both GE and the controls were given lists containing 3-5 items per trial. There were 24 trials at each list length. For one control, half the trials at each length were not tested due to experimenter error.

\subsubsection{Results}

Fig. 2 shows the percentage of words recalled in the correct position by GE and the controls. An independent samples $t$-test revealed that GE recalled significantly more known than degraded items, $t(70)=3.2, p=.002$ (combining list lengths 3,4 and 5 and treating lists as cases). At list length 4 , GE's recall was mildly impaired for known words, relative to the control sample $(t(7)=2.2, p=.04)$ and more substantially impaired for degraded words $(t(7)=4.5$, $p=.001$ ). At list length 5, however, GE showed substantial impairment for both known and degraded words $(t(8)>3.3, p<.006)$. When all list lengths were combined (i.e., 3-5 words for GE; 4-6 words for controls), GE did not show a significantly greater difference between the known and degraded items than the con- trols $(t(7)<1)$. Nevertheless, he did show this pattern when he was directly compared with control performance on list length 4 $(t(7)=2.1, p=.04)$.

Fig. 3 shows the percentage of words and nonwords recalled in the correct position by GE and the controls. Independent samples $t$-tests revealed that GE continued to show a significant lexicality effect (combining list lengths 3, 4 and 5 and treating lists as cases). His nonword recall was poorer than his recall of both known words $(t(106)=7.4, p<.0001)$ and semantically degraded words $(t(106)=4.1, p<.0001)$. Nevertheless, in contrast to his severe impairment of word recall, GE's ISR for nonwords was only mildly impaired. He showed no impairment of nonword recall relative to controls at list length $3(t(7)=1.3, p=.12)$, mild impairment that approached significance at list length $4(t(7)=1.6, p=.07)$ and abnormal performance at length $5(t(7)=2.3, p=.03)$. The size of the lexicality effect was significantly reduced for GE relative to the

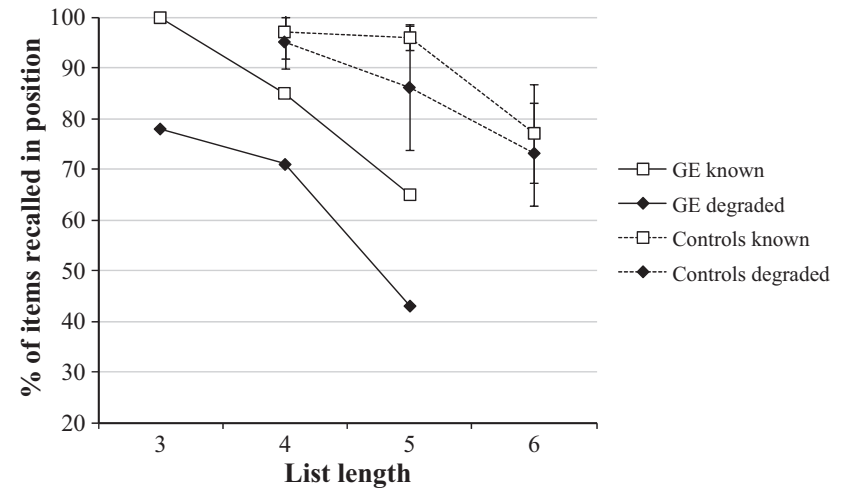

Fig. 2. Recall of known and semantically degraded words. Error bars show SE of mean. GE known: items that were relatively preserved for patient GE. GE degraded: items that were more semantically degraded. The same sets of words were presented to controls (giving rise to 'Controls known' and 'Controls degraded'). 


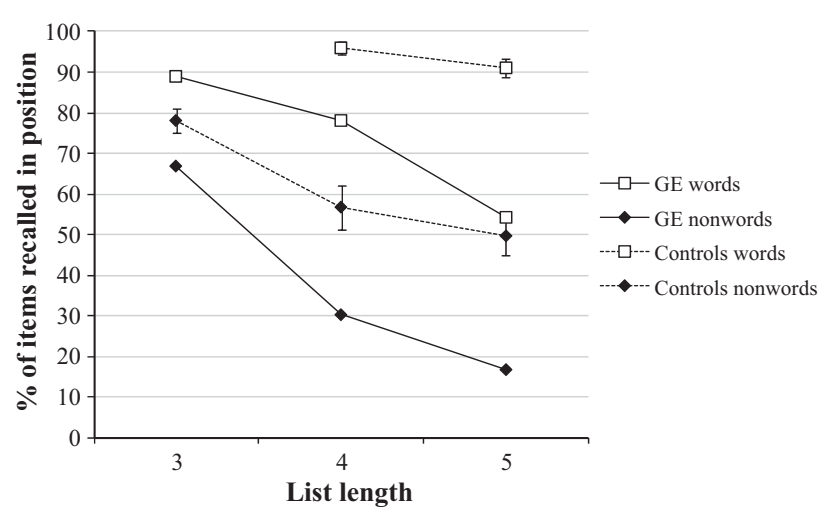

Fig. 3. Recall of words and nonwords. Error bars show SE of mean.

controls $(t(7)=5.0, p=.002$, combining lengths 4 and 5), in line with the proposal that patients with SD show reduced lexical/semantic support for STM. GE also exhibited no difference in recall accuracy between nonwords derived from known and degraded words, $t(70)<1$.

\subsubsection{Error analysis}

Incorrect responses were initially classified as order errors (i.e., target items produced in the wrong place in the sequence) and item errors (i.e., responses that were not target items at all). Item errors were further classified as phonological (sharing $50 \%$ or more of the phonemes from one of the targets), semantic (related in meaning to one of the targets), intrusions (targets from earlier lists) and repetitions (items produced earlier in the same list). Errors not fitting into any of these categories were classified as unrelated (i.e., less than $50 \%$ of phonemes shared). We also examined whether each phonological and unrelated error was a word or not. Positions without a response were marked as omissions.

There were few order errors; consequently the analysis below focuses on types of item error (see Table 2). GE showed a significant difference in his errors to known and degraded words, $\chi^{2}(3)=10.2$, $p=.02, N=78$. This analysis collapsed intrusions, repetitions and semantic errors into a single category and compared this with phonological errors, unrelated responses and omissions. Analysis of the standardised residuals suggested that GE made fewer phonological and more intrusion/semantic errors for known as opposed to degraded items (residuals $=-1.5$ and 2 respectively). When errors within these four categories were directly compared for GE and controls (summed across individuals in the control group and col-

Table 2

Errors to known and degraded words.

\begin{tabular}{llccr}
\hline & & GE & \multicolumn{2}{c}{ Controls } \\
\cline { 4 - 5 } & & & $M$ & s.d. \\
\hline \multirow{2}{*}{ Known } & & 4 & 3.5 \\
& Phonological & 15.4 & 5 & 7.6 \\
& Unrelated & 15.4 & 34 & 26.8 \\
\multirow{3}{*}{ Degraded } & Omission & 42.3 & 57 & 26.3 \\
& Other & 26.9 & 11 & 12.1 \\
& Phonological & $40.4^{\mathrm{a}}$ & 2 & 2.9 \\
& Unrelated & $21.2^{\mathrm{a}}$ & 37 & 22.6 \\
& Omission & 32.7 & 30 & 15.7 \\
& Other & 5.8 & 50 & 11.7 \\
& Phonological & 50.5 & 71 & 8.1 \\
& Unrelated & $32.8^{\mathrm{a}}$ & 15 & 10.9 \\
& Omission & 16.7 & 10 & 2.6 \\
\hline
\end{tabular}

This table shows each error type as a percentage of total errors.

a Cells in which the standardised residuals exceeded 2 when GE was compared with controls.
Table 3

Recall of nonwords with high and low phonotactic frequency.

\begin{tabular}{lcll}
\hline & GE & \multicolumn{2}{l}{ Controls } \\
\cline { 3 - 4 } & & $M$ & 67.2 \\
\hline High phonotactic frequency & 31.3 & 41.0 & 14.5 \\
Low phonotactic frequency & 0 & 10.5 \\
\hline This table shows percentage of nonwords recalled in the correct position.
\end{tabular}

lapsing across list lengths), there was a moderate difference in the error distribution for known words, $\chi^{2}(3)=9.3, p=.03, N=145$, and a more much substantial difference for semantically degraded words, $\chi^{2}(3)=70.4, p<.0001, N=264$. The standardised residuals suggested that GE made more phonological and unrelated errors than the controls (known words: 1.6 and 1.9; degraded words: 4.9 and 4.2) and fewer intrusion/semantic errors in the 'other' category (known words: -1.1 ; degraded words: -3.7 ). Finally, we examined the lexical status of phonological and unrelated errors for word recall (combining known and degraded word lists) and confirmed that GE made more nonword errors than the controls, $\chi^{2}(1)=3.9$ with continuity correction, $p=.05, N=74$.

GE also showed an abnormal error distribution for nonwords, $\chi^{2}(2)=29.6, p<.001, N=1047$ (including phonological, unrelated errors and omissions; there were very few errors in the 'other' category, which was dropped from the analysis). While the majority of nonword errors were phonological for both GE and the controls, the standardised residuals suggested that GE made more unrelated responses (3.6) and fewer phonological errors $(-2.8)$ compared with controls. Therefore, although GE's recall accuracy was only mildly impaired for nonwords, his errors preserved a smaller proportion of the target phonology.

\subsection{Phonotactic frequency}

\subsubsection{Method}

We replicated the experiment of Majerus et al. (2007) using their CVC nonwords which varied in phonotactic frequency, defined in terms of biphone frequency (i.e. frequent or infrequent CV and VC phoneme pairs). There were four nonwords per trial and eight trials per condition. Items were not repeated over the course of the experiment.

\subsubsection{Results}

Table 3 shows recall accuracy for high and low phonotactic frequency nonwords. An independent samples $t$-test revealed that GE recalled significantly more high than low phonotactic frequency nonwords $(t(14)=3.99, p<.001)$. Five of the controls also showed this pattern $(t(14)=2.18-3.38, p=.002-.023)$. RSDT revealed that the difference in recall between the high and low phonotactic frequency nonwords did not differ significantly between GE and controls $(t(7)<1)$.

\section{Experiment 1: Majerus nonword learning paradigm}

To investigate whether SD patients can learn new phonological forms, Majerus et al. (2007) repeatedly presented two small sets of five nonwords (one high and one low phonotactic frequency) for ISR. Each ISR list contained the same items in a different order. Recall was expected to improve on successive lists as the items were learned. Although the task was difficult for SD patients and controls, the healthy participants did show some learning, while the SD group did not. However, there were only six trials for each set of items, limiting the opportunity for learning. The current experiment used the same method and items, but presented more trials.

\subsection{Method}

The two sets each contained five nonwords. One set comprised nonwords with high phonotactic frequency, while the other contained low phonotactic frequency 


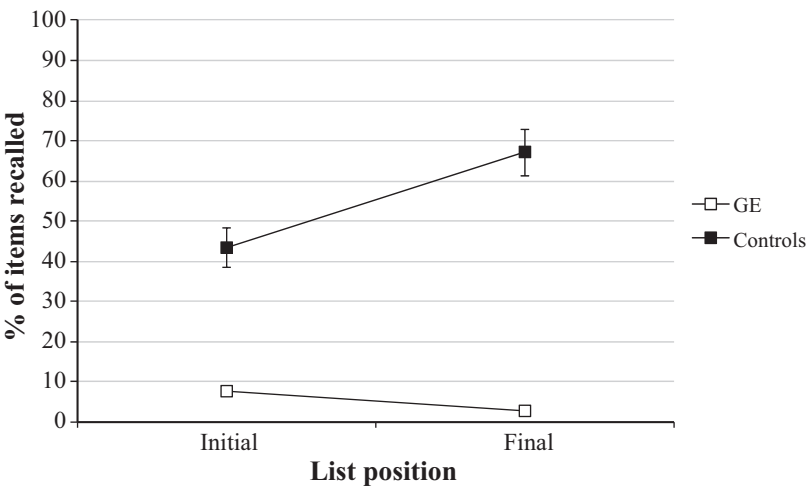

Fig. 4. Recall of nonwords from initial and final lists in the Majerus nonword learning paradigm (Experiment 1). Error bars show SE of mean. Initial lists were lists 1-4. Final lists were lists $6-10$.

items. All five nonwords were presented on every trial in a different serial order for ISR. There were ten trials per set (therefore each item was presented ten times). Participants were told that the same items would be repeated across lists. Their errors were not corrected.

\subsection{Results}

\subsubsection{Recall accuracy}

To test if learning had occurred, recall accuracy for the first four trials was compared with the last four trials of each set (i.e., lists 1-4 vs. 6-10; see Fig. 4). Repeated-measures ANOVA of the control data revealed a significant improvement in recall across the lists $(F(1,7)=72.2, p<.0001)$, a near-significant effect of phonotactic frequency (i.e., set 1 vs. set $2 ; F(1,7)=3.9, p=.09$ ) and no significant interaction. Therefore, subsequent analyses combined data from the two sets.

Fig. 4 shows the percentage of nonwords recalled by GE and the controls in the first and last four lists. GE's recall accuracy remained at floor and he showed no evidence of improved performance across the lists. His recall of the initial lists was moderately impaired $(t(7)=2.5, p=.02)$, while his performance on the final lists was more substantially impaired $(t(7)=3.8, p=.004)$. RSDT analysis revealed that GE showed a significantly smaller difference between the initial and final lists than the controls $(t(7)=2.2, p=.03)$. Therefore, in line with the findings of Majerus et al. (2007), GE did not show normal phonological learning of nonwords that were presented repeatedly.

\subsubsection{Error analysis}

There were very few order errors in the Majerus nonword learning task (only $2 \%$ for GE and $8 \%$ for controls); in contrast, there were significant numbers of item errors and omissions. The task provided substantial opportunity for participants to learn their own errors (as opposed to the target items) because (i) the ISR method generated a significant number of errors and (ii) no feedback about the accuracy of responses was provided. To investigate this possibility, each incorrect response was categorized according to whether it was novel or had already been produced by that participant. GE repeated $35 \%$ of his errors and controls displayed a similar pattern ( mean $=41 \%$; s.d. $=8.7$ ). GE showed no difference from the controls in the proportion of his errors that he repeated $(t(7)<1$, n.s.). Therefore, GE showed normal learning of his errors and this may have interfered with his ability to learn the target responses.

\section{Experiment 2: Hebb learning of digit lists}

Given GE's poor learning of repeatedly presented nonwords in Experiment 1, it is important to establish whether his sequence

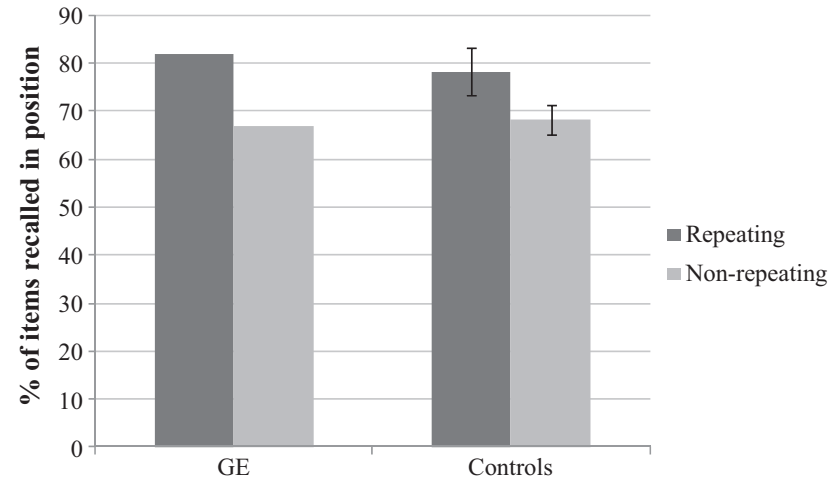

Fig. 5. Recall of Hebb digit lists (Experiment 2). Error bars show SE of mean.

learning is normal in other contexts. Majerus et al. (2007) reported that two SD patients showed normal learning of digit sequences using the Hebb procedure (see below), despite an apparent inability to learn nonword phonology. Therefore, we investigated whether GE would show normal learning of digit sequences. Given the excellent comprehension of numbers in SD, this experiment explored sequence learning for well-understood items.

\subsection{Method}

Hebb digit lists were presented for ISR. The lists contained single digit numbers (1-9) in a pseudorandom order (lists containing sequences such as 2, 3, 4, and 5 were re-randomised). Every third list was repeated, while the other sequences were novel. GE and controls were not informed about the repetition of sequences but they were expected to show implicit learning, leading to better recall accuracy for repeated than non-repeated lists (i.e., a Hebb effect). Each repeated list was presented eight times and then a block with a new repeated number sequence began. There were eight blocks in total.

The length of the lists was set according to GE's digit span. In the span test, two sequences were presented at each length and span was defined as the longest length for which one of the lists could be repeated correctly. GE had a digit span of 7 and, therefore, the Hebb digit lists contained eight items per trial (digit span +1 ). Five controls also had a digit span of 7 and the remaining three had spans of 5,8 and 9 respectively. The two controls with the highest spans showed ceiling effects throughout the experiment and were omitted from the analysis.

Prior to the experiment, we verified that GE showed good comprehension of number words: he scored 15/15 on both naming and word-picture matching tests for dot pictures. These tests included harder multi-digit numbers, such as 19 and 50 .

\subsection{Results}

\subsubsection{Recall accuracy}

The data are shown in Fig. 5. An independent samples $t$-test revealed a significant Hebb effect (a recall advantage for repeated over non-repeated trials) for GE $(t(120)=3.13, p=.001)$ and for three of the six controls $(t(120)>2.38, p<.009)$. GE was not significantly impaired at producing either the repeating or non-repeating lists $(t(5)<1)$. Moreover, RSDT revealed that the size of the Hebb effect was equivalent in GE and controls $(t(5)<1)$.

\subsubsection{Error analysis}

Table 4 shows the proportion of order errors, item errors and omissions for repeated and non-repeated trials. When repeating digit sequences, GE and the controls produced substantial numbers of order errors as well as omissions and item errors (all of which were digit names). The proportion of errors in each category did not differ between GE and the controls $(t(5)<1)$. GE produced fewer order errors for repeated than for non-repeated trials $\left(\chi^{2}(2)=11.6\right.$, $p=.003, N=275$ ), supporting the conclusion that he was able to learn the digit sequences. 
Table 4

Errors in Hebb digit and CV nonword lists (Experiments 2 and 3).

\begin{tabular}{|c|c|c|c|c|c|c|}
\hline & \multicolumn{2}{|l|}{ GE } & \multicolumn{4}{|c|}{ Controls } \\
\hline & \multirow[t]{2}{*}{ Repeating } & \multirow[t]{2}{*}{ Non-repeating } & \multicolumn{2}{|c|}{ Repeating } & \multicolumn{2}{|c|}{ Non-repeating } \\
\hline & & & $M$ & s.d. & $M$ & s.d. \\
\hline \multicolumn{7}{|c|}{ Digits (Experiment 2) } \\
\hline Order & 0.24 & 0.44 & 0.47 & 0.31 & 0.53 & 0.24 \\
\hline Item & 0.24 & 0.27 & 0.23 & 0.11 & 0.21 & 0.10 \\
\hline Omission & 0.52 & 0.29 & 0.30 & 0.31 & 0.27 & 0.32 \\
\hline \multicolumn{7}{|c|}{ CV nonwords (Experiment 3 ) } \\
\hline Order & 0.12 & 0.05 & 0.07 & 0.14 & 0.03 & 0.04 \\
\hline Item & 0.82 & 0.85 & 0.93 & 0.16 & 0.92 & 0.10 \\
\hline Omission & 0.05 & 0.10 & 0.01 & 0.02 & 0.05 & 0.08 \\
\hline
\end{tabular}

This table shows proportion of errors to repeating and non-repeating lists that were order errors, item errors and omissions.

\section{Experiment 3: Hebb learning of $\mathrm{CV}$ nonwords}

The contrast between Experiments 1 and 2 poses a puzzle: if phonological STM and sequence learning are largely preserved in SD, why does patient GE fail to learn phonological sequences in the Majerus nonword learning task? The remainder of this study was focussed on resolving this issue. There are several differences between Experiments 1 and 2 in task design and materials: (1) in the Hebb digit experiment, a complete sequence was repeated, while in the Majerus ISR experiment, the sequence of items was in a different order. (2) Learning in the Hebb digit experiment was incidental - participants were typically unaware that sequences were repeated. In contrast, participants were aware that items were repeated in the Majerus ISR experiment and, therefore, controls might have successfully engaged effortful learning strategies that were impaired in GE. (3) The Hebb experiment presented highly familiar items (digits), while the Majerus ISR experiment involved novel items (nonwords). Consequently, while sequence errors were frequent in the Hebb experiment, participants almost exclusively produced item errors and omissions in the Majerus ISR experiment.

In the next two experiments, we explored the circumstances in which GE could and could not learn new verbal sequences. First, we examined learning of $\mathrm{CV}$ nonwords using a Hebb procedure to allow comparison with Experiment 2. We used a span procedure to determine list length in both experiments (i.e., Hebb sequences were set at span +1 ); therefore task difficulty was broadly equated for GE across the digit and CV nonword lists. Moreover, the items in the two experiments were largely equivalent in terms of set size, item length/complexity and phonological similarity (as the majority of digit names have a simple CV structure and involve different vowel sounds). As a result, the primary remaining difference between Experiments 2 and 3 was in the familiarity of the items (digits vs. nonwords).

\subsection{Method}

The experiment followed the procedure described for Experiment 2. The lists comprised the following CV syllables: zee, rarr, gare, tay, kye, cherr, fu, poe. CV nonword span was determined using the method above and was found to be 3 items for GE: therefore, the Hebb CV lists were four items long. Four controls had a CV nonword span of 3, two had a span of 4 and two had a span of 5 .

\subsection{Results}

\subsubsection{Recall accuracy}

The data are shown in Fig. 6. An independent samples $t$-test revealed that GE failed to show a significant Hebb effect, $t(120)<1$. Four of the eight controls did show a significant Hebb effect: $t(120)=3.87-1.69, p=.0001-.047$. GE's recall accuracy was significantly impaired for the repeating lists $(t(7)=2.3, p=.03)$ and

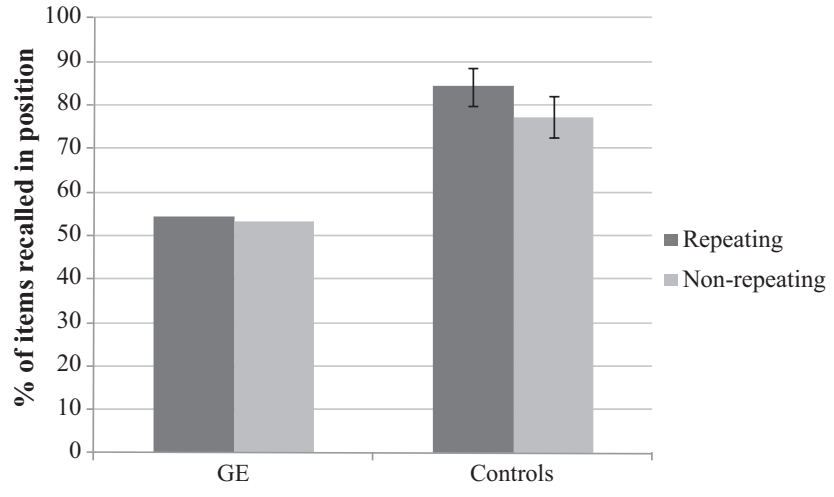

Fig. 6. Recall of Hebb CV nonword lists (Experiment 3). Error bars show SE of mean.

marginally impaired for the non-repeating lists $(t(7)=1.7, p=.06)$. However, RSDT revealed that there was no significant difference in the size of the Hebb effect for GE and controls $(t(7)<1)$.

\subsubsection{Error analysis}

For both GE and the controls, the majority of errors to CV nonword lists were item errors - there were few order errors in contrast to the digit lists (see Table 4). Both GE and the controls showed a highly significant difference between the rates of order, item and omission errors across the digit and CV nonword sets (collapsing across repeating and non-repeating lists, GE: $\chi^{2}(2)=165.2, p<.001$, $N=501$; controls: $\chi^{2}(2)=1085.6, p<.001, N=2465$ ).

The proportion of errors in each category did not differ between $\mathrm{GE}$ and the controls for $\mathrm{CV}$ nonwords $(t(7)<1)$. The difference in GE's errors to repeated and non-repeated items approached significance (GE: $\chi^{2}(2)=5.6, p=.06, N=226$ ): the largest standardised residual suggested that there may have been more order errors for repeated lists (1.7). The controls also showed a significant difference between repeated and non-repeated lists $\left(\chi^{2}(2)=10.7\right.$, $p=.005, N=794)$ : analysis of the standardised residuals suggested that they made fewer omission errors for the repeated lists (residual $=-2.5$ ), although this error type was uncommon overall.

A more detailed analysis of errors suggested that GE and the controls were learning their own errors. Each incorrect response was categorized according to whether it was novel or had already been produced by that participant. A total of $52.8 \%$ of GE's errors were repeats and controls displayed a similar pattern (mean $=32.9 \%$; s.d. $=8.82$ ). GE repeated a higher proportion of his errors and this difference approached significance $(t(7)=2.1, p=.07$, two-tailed test). Therefore, as in other nonword experiments, GE was able to learn his errors and this may have interfered with his ability to learn the target responses.

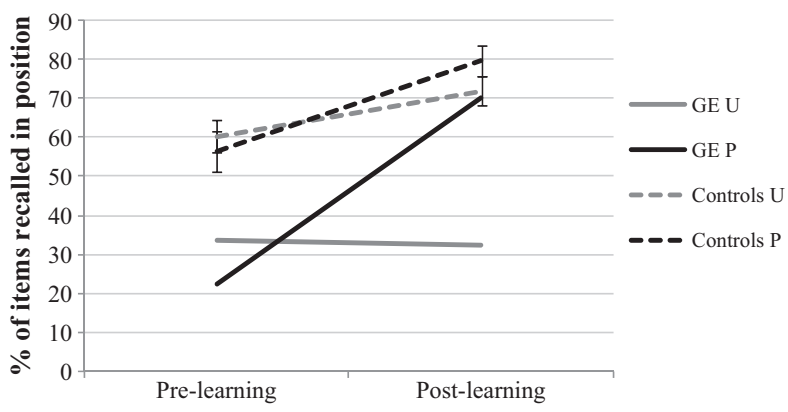

Fig. 7. Recall accuracy for practiced and unpracticed nonwords using an errorless learning procedure (Experiment 4). Error bars show SE of mean. U: unpracticed set; P: practiced set. 


\section{Experiment 4: nonword learning in an error-reducing paradigm}

The previous experiment established that learning of unfamiliar nonwords is not strong or reliable even in healthy subjects using the Hebb procedure. It seems that the use of novel items in ISR generated huge potential for item errors, which GE and control participants were likely to learn instead of the target items. In the final experiment, therefore, we used an error-reducing learning procedure (Baddeley \& Wilson, 1994; Fillingham, Hodgson, Sage, \& Lambon Ralph, 2003). Participants were initially asked to repeat single nonwords and any errors were immediately corrected. When participants could repeat each of the targets correctly, they were trained on pairs and then triplets of items (again until their performance was virtually flawless). We used the Majerus nonwords from Experiment 1 to allow direct comparison of learning for this nonword set via two different methods.

\subsection{Method}

GE and the controls were trained on two sets of items, each containing five high phonotactic frequency nonwords also used in Experiment 1 (generated by Majerus et al., 2007). There were three phases to the procedure: (1) participants were given a pre-learning ISR baseline test. This involved repeating sequences of items drawn from the 'practiced' or 'unpracticed' sets before these items were trained. (2) In a subsequent session, participants were trained to produce the items in each practiced set. We used a stepwise procedure to limit the production of errors. First, participants repeated single items spoken by the experimenter. Once they had provided a correct response for each item three times, they moved on to trials containing two items. When three blocks of five nonword pairs had been recalled correctly, they moved on to three items per trial. If, however, more than one error occurred within a block, the experimenter returned to one fewer items per trial, before repeating the procedure. Any errors were immediately corrected. (3) Once the participant had produced three blocks at list length three with relatively few errors, a post-learning ISR test was performed. The pre- and post-learning tests involved twenty lists for ISR (ten for each of the practiced and unpracticed sets). The lists contained four items.

\subsection{Results}

\subsubsection{Recall accuracy}

The two sets of practiced and unpracticed items were combined to increase the number of items in the analysis. ANOVA (treating lists as cases) was used to examine the influence of two factors on GE's recall: experiment phase (pre-learning vs. post-learning ISR) and practice set (unpracticed vs. practiced). The findings are shown in Fig. 7. GE showed significant learning, revealed by an interaction between phase and practice set, $F(1,76)=23.4, p<.001$, plus main effects of phase $(F(1,76)=21.1, p<.001)$ and $\operatorname{set}(F(1,76)=6.8$, $p=.01)$. Likewise, the control group showed significant learning: repeated-measures ANOVA revealed an interaction between phase and practice set, $F(1,7)=6.4, p=.04$, plus a main effect of phase, $F(1,7)=17.8, p=.004$. GE's ISR performance was within normal limits on the practiced set after learning $(t(7)<1)$ but was otherwise significantly impaired $(t(7)>2.2, p<.03)$. Nevertheless, RSDT revealed that GE and controls showed a comparable degree of learning: they showed an equivalent difference between the pre- and post-learning phases for the practiced $\operatorname{set}(t(7)=1.0$, n.s.).

\subsubsection{Error analysis}

There were few order errors for both GE and the controls (approximately $1 \%$ of errors were of this type); therefore, this analysis examined item errors. There were no significant differences in the numbers of phonological, unrelated and omission errors made by GE and controls in the pre-and post-learning tests for practiced items, indicating that training did not have a strong effect on the types of errors $\left(\chi^{2}(2)<1, N=96\right.$ for GE and 394 for controls). Both GE and the controls mainly produced phonological and unrelated responses - omissions of items were relatively uncommon. However, GE did show an abnormal error distribution for the practiced nonwords when compared with controls (pre-learning test: $\chi^{2}(2)=14.1, p=.001, N=333$; post-learning test: $\chi^{2}(2)=10.1$, $p=.006, N=144)$. Analysis of the standardised residuals suggested that, in line with ISR for known/degraded items, GE made more unrelated errors than controls (residuals for pre- and post-learning tests were 3.1 and 2.6 respectively).

\section{Discussion}

We investigated the ability of SD patient GE to maintain and learn phonological sequences under different circumstances, in order to examine the relationship between working memory (WM) and long-term phonological learning. Like previously studied cases (see Jefferies et al., 2005), GE showed good immediate serial recall (ISR) for meaningless nonwords and well-understood items such as number words (whose magnitude meanings were unaffected by GE's anterior temporal lobe atrophy). This suggests that the STM processes that maintain phonological information were largely spared. However, GE showed a reduced semantic contribution to ISR, resulting in poorer recall of semantically degraded than better understood words. He produced frequent phonological and unrelated errors in word recall, particularly for items he no longer fully understood. He also showed a reduced lexicality effect because he made numerous phonological and unrelated errors to both words and nonwords, while healthy participants predominantly made these errors to nonwords. These findings indicate that GE showed the same profile of strengths and weaknesses in verbal STM as previously studied SD patients (e.g., Hoffman et al., 2009; Jefferies, Jones, et al., 2004; Jefferies et al., 2005; Knott et al., 1997; Patterson et al., 1994).

Despite GE's substantial impairment in word ISR, several experimental findings supported the conclusion that his phonological STM was operating relatively normally (at least for meaningless and semantically preserved items). He showed normal effects of phonological similarity on letter recall - i.e., poorer recall of phonologically confusable letters such as G, T, B, V, and P, as opposed to more distinct-sounding items, such as J, M, O, C, and R - suggesting that he continued to use a phonological code to support ISR (see also Jefferies et al., 2005; Knott et al., 2000; Majerus et al., 2007; McCarthy \& Warrington, 2001). In addition, he showed normal effects of phonotactic frequency in nonword ISR: he was better at repeating sequences of nonwords that contained common phoneme combinations, as opposed to unusual arrangements of phonemes (see also Majerus et al., 2007). This finding shows that GE's verbal STM was able to benefit from long-term phonological knowledge, even though other facets of long-term linguistic knowledge (i.e., lexical-semantic information) only made a limited contribution to ISR.

The pattern shown by patient GE - i.e., good phonological retention but phonological errors during ISR for semantically degraded words - can be readily explained within the theoretical framework put forward by Patterson et al. (1994). Patterson and colleagues proposed that verbal STM emerges from interactions between phonological and semantic representations and that each of these systems provides an important source of constraint on phonological maintenance. According to this and related viewpoints, the phonological system - characterised as emerging from interactions between speech perception and production - underpins the maintenance of phonological sequences in STM (Acheson \& MacDonald, 2009; Jacquemot \& Scott, 2006). This same system develops pattern-completion properties for phonological sequences that are presented frequently - i.e., it captures longterm sub-lexical and lexical-phonological knowledge, giving rise to phonotactic frequency effects and contributing to lexicality effects in ISR and speech production (Acheson \& MacDonald, 2009). As 
the phonological system is intact in SD, patients show (i) normal phonological production, (ii) preserved phonological maintenance in STM and (iii) an intact ability to benefit from long-term phonological knowledge in ISR tasks.

In contrast, SD patients show a reduction in the second source of constraint on phonological maintenance, arising from the interaction between semantics and phonology. Patterson et al. (1994) refer to this as "semantic binding" (see also Jefferies et al., 2006). In essence, bidirectional links between the semantic and phonological systems ensure that phonological representations of words and their corresponding meanings are co-activated during speech comprehension and production. In healthy participants, this allows word span to be greater than nonword span because ongoing activation of a word's meaning places strong constraints on the identity and ordering of its phonemes. When these semantic constraints are reduced - for example, when SD patients attempt to recall semantically degraded words - frequent phoneme migrations occur. Although semantic binding is critically important in demanding tasks like ISR which require the phonology of several items to be maintained simultaneously, it is also at play during phonological production more widely, in line with the framework above. Nevertheless, the spontaneous speech of SD patients remains largely free from phonological errors, presumably because (i) patients rarely attempt to produce words that are poorly understood (whereas they can be provided with the phonology of these items in ISR) and (ii) the context supports activation of residual meanings for the words SD patients produce in conversation.

We then considered the consequences of this language profile i.e., intact phonological architecture combined with eroded semantic binding - for the long-term learning of phonological sequences in SD in four experiments. Although SD patients would presumably show severe impairment in new word learning, since this requires the formation of links between phonological forms and semantic representations (and possibly also new semantic learning; see Murray, Koenig, Antani, McCawley, \& Grossman, 2007), we might expect individuals with SD to show largely normal long-term learning of phonological sequences if this ability relies on the same mechanisms as phonological STM. Many neuropsychological and developmental studies have pointed to a causal link between these two skills (see Introduction), yet the issue of whether SD patients can learn new phonological forms has scarcely been investigated. Moreover, Majerus et al. (2007) found that two cases with SD failed to show improvement when they were repeatedly presented with the same nonwords for ISR, despite showing normal incidental learning of digit sequences in the Hebb learning paradigm. This pattern of findings is surprising because the patients were attempting to learn meaningless phonological forms and thus intact phonological STM might be expected to be sufficient for normal performance (however, see below for other possibilities).

We replicated the findings of Majerus et al. (2007) in our patient GE (Experiments 1 and 2) and then explored the circumstances in which GE did and did not show normal learning of phonological sequences. Two key findings emerged: (1) GE demonstrated normal long-term learning of serial order information when he was presented with sequences of highly familiar, semantically intact items such as number words (Experiment 2). In contrast, he did not show significant learning of CV nonwords in the same experimental paradigm, even when task difficulty, phonological similarity/complexity and set size were broadly equated (Experiment 3). This suggests that long-term sequence learning is partly dependent on semantic binding - GE was only able to learn sequences of highly coherent items for which phoneme migration and phoneme identity errors were rare. Healthy controls also found it challenging to learn sequences of nonwords because, like GE, they made frequent phonological errors to these items. In line with this explanation, order errors (i.e., target items recalled in the wrong place in the sequence) were frequent for digit lists (Experiment 2) but rare for nonwords (Experiment 3), for both GE and controls. For digit lists, participants had to learn the order of highly familiar and phonologically strong items - and consequently, when they made errors, they often misremembered the order of the items in the list. For unfamiliar nonwords, in contrast, the greatest demands on serial order were in maintaining the sequence of phonemes within and between items - consequently GE and the controls frequently produced phoneme migrations (as well as phoneme identity errors) resulting in 'item' errors that interfered with their ability to learn the target items.

(2) GE showed much better long-term learning of nonwords in tasks designed to minimise the opportunity to make errors. He failed to acquire nonwords in experiments that relied on ISR in the learning phase, even when very small set sizes were used and each nonword was presented frequently (Experiments 1 and 3 ). Error analyses suggested that, in these experiments, GE and the controls showed a tendency to learn their own errors as opposed to the target items (see Couture, Lafond, \& Tremblay, 2008, for related findings). Therefore, GE showed phonological learning (of his errors) which did not produce improvements in recall accuracy. In contrast, he showed much better performance - i.e., substantial learning that did not differ from controls - when a stepwise procedure was used to train individual items and then pairs in a relatively errorless fashion (Experiment 4).

These findings suggest that while intact phonological STM is necessary for the acquisition of new phonological forms, this capacity is not always sufficient for normal learning. Since the semantic binding of phonology provides a basis for the prevention of item errors in verbal STM, conceptual knowledge can facilitate verbal sequence learning (as in Experiments 2 vs. 3 employing digits and CV nonwords). In addition, the fact that an error-reducing paradigm led to better learning of meaningless phonological forms in GE suggests that the ATL region, which is the focus of atrophy in SD, might play a wider role in controlling errors in ISR and verbal learning. Although the items to be learned were meaningless, GE made significantly more phonological errors than control participants across the experiments, especially on longer lists, and he also made more substantial errors (i.e., more unrelated as opposed to phonological errors in several experiments). This impairment of nonword ISR appears to have had notable consequences for the nonword learning tasks: for example, GE may have been significantly impaired on the phonological learning paradigm used in Experiment 1 because his failure to repeat these items correctly would have severely limited his opportunity to learn the nonwords, relative to controls.

What might account for GE's difficulties repeating longer lists of nonwords? It seems unlikely that GE's atrophy was starting to encroach on phonological regions, given that (i) he continued to have fluent, well-formed speech largely free from phonological errors, and (ii) he showed normal effects of phonological similarity and phonotactic frequency in ISR. Therefore, given the intimate connection between semantics and phonology, it is possible that short-term retention and long-term learning of meaningless phonological sequences cannot proceed normally in the face of substantial semantic degradation in SD (especially when sequences exceed the capacity of phonological STM; see Jefferies et al., 2005). In other words, healthy participants might ordinarily recruit lexical/semantic representations to support nonword ISR/learning in a way that is not available to SD patients.

Experimental investigations of healthy participants have shown that nonword recall is influenced by lexical as well as sublexical knowledge: nonwords with more real-word neighbours are recalled better than those with fewer neighbours, even when phonotactic frequency is held constant (Roodenrys \& Hinton, 2002; Thorn \& Frankish, 2005). Within the semantic binding framework above (Patterson et al., 1994), this lexical-level effect on 
nonword recall could partially arise from the phonological layer but might also draw on interactions with the semantic system. The nonword "lat", for example, might benefit from similarity with the phonological neighbours "hat", "lot" and "lad" their activation would strengthen phonological elements duplicated in the target (and across all of the neighbours, this would strengthen the entire target). Additionally, Thorn and Frankish (2005) noted that phonological representations of nonwords might activate lexical-semantic representations of word neighbours by this mechanism, nonwords with large neighbourhoods would be strengthened by more lexical-semantic connections, leading to superior recall. Patients with SD would presumably retain fewer lexical-semantic connections, potentially resulting in mild impairment of nonword recall. In line with these ideas, semantically impaired patients (including those with SD) can show poorer ISR for nonwords that are phonologically similar to semantically degraded as opposed to better-understood words (Caza, Belleville, \& Gilbert, 2002; Jefferies et al., 2005).

It is also interesting to consider these findings within a conceptual framework proposed by Knott and Marslen-Wilson (2001), which examines the role of the medial temporal lobe (MTL) in binding together semantic and phonological representations during word learning and supra-span ISR. According to this view, ISR tasks automatically activate phonological and semantic representations - therefore direct connections between these cortical representations are vital for the recall of familiar words (as proposed above). However, for long lists that exceed the capacity of phonological STM, MTL structures play an important role by rapidly associating semantic knowledge with the appropriate phonological form. Moreover, in new word learning, associations acquired by the MTL are crucial until the process of consolidation, when direct connections between semantic and phonological representations can be formed. In patients with SD, there is disruption not only of direct interactions between semantics and phonology; in the face of severe semantic degradation, the MTL can no longer form rapid associations between phonological forms and semantic representations. Given that healthy participants draw on lexical/semantic representations to support supra-span ISR and learning of nonwords, a loss of semantic input to the MTL might contribute to GE's difficulties in both the repetition of longer nonword sequences and the nonword learning tasks.

In conclusion, this study found that although patient GE showed impaired nonword learning in some contexts, normal acquisition of phonological sequences could occur when the production of item errors was minimised in one of two ways. First, sequence learning was substantial for familiar, semantically intact items but much poorer for nonwords, suggesting that semantic binding can facilitate sequence learning by preventing item errors. Secondly, nonword learning was greatly improved by the use of a stepwise training procedure that minimised the production of item errors. In contrast, nonword learning was negligible in training tasks that relied on error-prone ISR. Therefore, although semantic impairment may disrupt processing within the phonological system (giving rise, for example, to frequent phonological errors in ISR for semantically degraded words), SD patients retain the ability to learn new phonological sequences, as predicted by their intact phonological STM and relatively preserved MTL.

\section{Acknowledgements}

We would like to thank GE and his wife for their help with this project and Mark Doran and colleagues at the Walton Centre for Neurology and Neurosurgery, Liverpool, UK for referring the patient to us. The research was supported by an MRC programme grant (G0501632).

\section{Appendix A. GE's description of the 'Cookie Theft' picture}

“... this is obviously where you do your washing, but the water's coming out all on to the floor! Isn't it like, it's where you do your washing in your ... um, you know, your what's-its-name, in there, where you make your cook, you know when you do your cooking and things like that. So this is where you do your washing and your washing's falling out all over, and I'm just amazed with that - I can tell why she's not smiling! 'Cause like I said, this is where you put your stuff in, and this where you put in to your cooking place, and then this person up here, I'm amazed why he's not fell, 'cause he's only, he's slipped-ed back slightly while he's picking up some food, 'cause he's getting some food from there to put it down, to help it with the other one, "cause this is again where you open them up and this is where you store your food..."

\section{References}

Acheson, D. J., \& MacDonald, M. C. (2009). Verbal working memory and language production: Common approaches to the serial ordering of verbal information. Psychonomic Bulletin, 135, 50-68.

Baddeley, A. D. (1966). Short-term memory for word sequences as a function of acoustic, semantic and formal similarity. Quarterly Journal of Experimental Psychology, 18, 362-365.

Baddeley, A. D., Gathercole, S. E., \& Papagno, C. (1998). The phonological loop as a language learning device. Psychological Review, 105, 158-173.

Baddeley, A. D., Papagno, C., \& Vallar, G. (1988). When long-term learning depends on short-term storage. Journal of Memory and Language, 27, 586-595.

Baddeley, A., \& Wilson, B. A. (1994). When implicit learning fails: Amnesia and the problem of error elimination. Neuropsychologia, 32, 53-68.

Bozeat, S., Lambon Ralph, M. A., Patterson, K., Garrard, P., \& Hodges, J. R. (2000). Nonverbal semantic impairment in semantic dementia. Neuropsychologia, 38(9), 1207-1215.

Cappelletti, M., Kopelman, M., \& Butterworth, B. (2002). Why semantic dementia drives you to the dogs (but not to the horses): A theoretical account. Cognitive Neuropsychology, 19, 483-503.

Caza, N., Belleville, S., \& Gilbert, B. (2002). How loss of meaning with preservation of phonological word form affects immediate serial recall performance: A linguistic account. Neurocase, 8, 255-273.

Chan, D., Fox, N. C., Scahill, R. I., Crum, W. R., Whitwell, J. L., Leschziner, G., et al. (2001). Patterns of temporal lobe atrophy in semantic dementia and Alzheimer's disease. Annals of Neurology, 49, 433-442.

Conrad, R. (1964). Acoustic confusion in immediate memory. British Journal of Psychology, 55, 75-84

Conrad, R., \& Hull, A. J. (1964). Information, acoustic confusion and memory span. British Journal of Psychology, 55, 439-432.

Couture, M., Lafond, D., \& Tremblay, S. (2008). Learning correct responses and errors in the Hebb repetition effect: Two faces of the same coin. Journal of Experimental Psychology: Learning Memory and Cognition, 34(3), 524-532.

Crawford, J. R., \& Garthwaite, P. H. (2002). Investigation of the single case in neuropsychology: Confidence limits on the abnormality of test scores and test score differences. Neuropsychologia, 40(8), 1196-1208.

Crawford, J. R., \& Garthwaite, P. H.(2005). Testing for suspected impairments and dissociations in single-case studies in neuropsychology: Evaluation of alternatives using Monte Carlo simulations and revised tests for dissociations. Neuropsychology, 19, 318-331.

Fillingham, J. K., Hodgson, C., Sage, K., \& Lambon Ralph, M. A. (2003). The application of errorless learning to aphasic disorders: A review of theory and practice. Neuropsychological Rehabilitation, 13, 337-363.

Gathercole, S. E., \& Baddeley, A. D. (1989). Evaluation of the role of phonological STM in the development of vocabulary in children: A longitudinal study. Journal of Memory Language, 28, 200-213.

Gathercole, S. E., Hitch, G. J., Service, E., \& Martin, A. J. (1997). Short-term memory and new word learning in children. Developmental Psychology, 33, 966-979.

Gathercole, S. E., Willis, C., Emslie, H., \& Baddeley, A. D. (1992). Phonological memory and vocabulary development during the early school years: A longitudinal study. Developmental Psychology, 28, 887-898.

Graham, K. S., Patterson, K., Pratt, K. H., \& Hodges, J. R. (2001). Can repeated exposure to "forgotten" vocabulary help alleviate word-finding difficulties in semantic dementia? An illustrative case study. Neuropsychological Rehabilitation, 11, 429-454.

Green Heredia, C., Sage, K., Lambon Ralph, M. A., \& Berthier, M. (2008). Relearning and retention of verbal labels in a case of semantic dementia. Aphasiology, 22, $1-18$.

Gupta, P. (2003). Examining the relationship between word learning, nonword repetition, and immediate serial recall in adults. Quarterly Journal of Experimental Psychology, 56A, 1213-1236.

Gupta, P., \& Tisdale, J. (2009). Word learning, phonological short-term memory, phonotactic probability and long-term memory: Towards an integrated frame- 
work. Philosophical transactions of the Royal Society B: Biological Sciences, 364, 3755-3771.

Henry, M. L., Beeson, P. M., \& Rapcsak, S. Z. (2008). Treatment for lexical retrieval in progressive aphasia. Aphasiology, 22, 826-838.

Hodges, J. R., Patterson, K., Oxbury, S., \& Funnell, E. (1992). Semantic dementia: Progressive fluent aphasia with temporal lobe atrophy. Brain, 115, 1783-1806.

Hoffman, P., Jefferies, E., Eshan, S., Jones, R. W., \& Lambon Ralph, M. A. (2009). Semantic memory is key to binding phonology: Converging evidence from immediate serial recall in semantic dementia and healthy participants. Neuropsychologia, 47, 747-760.

Howard, D., \& Patterson, K. (1992). Pyramids and palm trees: A test of semantic access from pictures and words. Bury, St Edmunds, UK: Thames Valley Test Company.

Goodglass, H., \& Kaplan, E. (1983). The assessment of aphasia and related disorders. Philadelphia: Lea \& Febiger.

Jacquemot, C., \& Scott, S. K. (2006). What is the relationship between phonological short-term memory and speech processing? Trends in Cognitive Sciences, 10 480-486.

Jefferies, E., Frankish, C., \& Lambon Ralph, M. A. (2006). Lexical and semantic binding in verbal short-term memory. Journal of Memory and Language, 54, 81-98.

Jefferies, E., Jones, R., Bateman, D., \& Lambon Ralph, M. A. (2004). When does word meaning affect immediate serial recall in semantic dementia? Cognitive, Affective and Behavioral Neuroscience, 4(1), 20-42.

Jefferies, E., Jones, R. W., Bateman, D., \& Lambon Ralph, M. A. (2005). A semantic contribution to nonword recall? Evidence for intact phonological processes in semantic dementia. Cognitive Neuropsychology, 22(2), 183-212.

Jefferies, E., Patterson, K., Jones, R. W., Bateman, D., \& Lambon Ralph, M. A. (2004). A category-specific advantage for numbers in verbal shortterm memory: Evidence from semantic dementia. Neuropsychologia, 42(5), term me-660.

Jefferies, E., Patterson, K., Jones, R. W., \& Lambon Ralph, M. A. (2009). Comprehension of concrete and abstract words in semantic dementia. Neuropsychology, 23, 492-499.

Jokel, R., Rochon, E., \& Anderson, N. D. (2010). Errorless learning of computergenerated words in a patient with semantic dementia. Neuropsychological Rehabilitation, 20, 16-41.

Jokel, R., Rochon, E. A., \& Leonard, C. (2006). Treatment for anomia in semantic dementia: Improvement, maintenance or both? Neuropsychological Rehabilitation, 16, 241-256.

Kay, J., Lesser, R., \& Coltheart, M. (1992). Psycholinguistic Assessments of Language Processing in Aphasia (PALPA). Hove, UK: Lawrence Erlbaum Associates.

Kertesz, A., Jesso, S., Harciarek, M., Blair, M., \& McMonagle, P. (2010). What is semantic dementia? A cohort study of diagnostic features and clinical boundaries. Archives of Neurology, 67, 483-489.

Knott, R., \& Marslen-Wilson. (2001). Does the medial temporal lobe bind phonological memories. Journal of Cognitive Neuroscience, 13(5), 593-609.

Knott, R., Patterson, K., \& Hodges, J. R. (1997). Lexical and semantic binding effects in short-term memory: Evidence from semantic dementia. Cognitive Neuropsychology, 14(8), 1165-1216.

Knott, R., Patterson, K., \& Hodges, J. R. (2000). The role of speech production in auditory-verbal short-term memory: Evidence from progressive fluent aphasia. Neuropsychologia, 38, 125-142.

Lambon Ralph, M. A., \& Patterson, K. (2008). Generalization and differentiation in semantic memory: Insights from semantic dementia. Annals of the New York Academy of Sciences, 1124, 61-76.
Leclercq, A. L., \& Majerus, S. (2010). The relationship between serial order STM and vocabulary development: A longitudinal study. Developmental Psychology, 46, 417-427.

Majerus, S., Norris, D., \& Patterson, K. (2007). What does a patient with semantic dementia remember in verbal short-term memory? Order and sound but not words. Cognitive Neuropsychology, 24, 131-151.

Majerus, S., Poncelet, M., Van der Linden, M., \& Weekes, B. (2008). Lexical learning in bilingual adults: The relative importance of short-term memory for serial orde and phonological knowledge. Cognition, 107, 395-419.

McCarthy, R. A., \& Warrington, E. K. (2001). Repeating without semantics: Surface dysphasia? Neurocase, $7,77-87$.

Mosse, E. K., \& Jarrold, C. (2008). Hebb learning, verbal short-term memory, and the acquisition of phonological forms in children. Quarterly Journal of Experimental Psychology, 61, 505-514.

Mummery, C. J., Patterson, K., Price, C. J., Ashburner, J., Frackowiak, R. S. J., \& Hodges, J. R. (2000). A voxel-based morphometry study of semantic dementia: Relationship between temporal lobe atrophy and semantic memory. Annals of Neurology, 47(1), 36-45.

Murray, R., Koenig, P., Antani, S., McCawley, G., \& Grossman, M. (2007). Lexical acquisition in progressive aphasia and frontotemporal dementia. Cognitive $\mathrm{Neu}$ ropsychology, 24, 48-69.

Nestor, P. J., Fryer, T. D., \& Hodges, J. R. (2006). Declarative memory impairments in Alzheimer's disease and semantic dementia. Neuroimage, 30(3), 1010-1020.

Patterson, K., Graham, N., \& Hodges, J. R. (1994). The impact of semantic memory loss on phonological representations. Journal of Cognitive Neuroscience, 6(1), 57-69.

Patterson, K., \& Hodges, J. R. (1992). Deterioration of word meaning: Implications for reading. Neuropsychologia, 30, 1025-1040.

Patterson, K., Lambon Ralph, M. A., Jefferies, E., Woollams, A., Jones, R. W., Hodges, J. R., et al. (2006). "Presemantic" cognition in semantic dementia: Six deficits in search of an explanation. Journal of Cognitive Neuroscience, 18, 169-183.

Patterson, K., \& Marcel, A. J. (1992). Phonological alexia or phonological alexia? In J. Alegria, D. Holender, J. Junca de Morais, \& M. Radeau (Eds.), Analytic approaches to human cognition (pp. 259-274). Amsterdam: Elsevier.

Raven, J. C. (1962). Coloured progressive matrices sets $A, A B, B$. London: H. K. Lewis.

Reilly, J., Martin, N., \& Grossman, M. (2005). Verbal learning in semantic dementia: Is repetition priming a useful strategy? Aphasiology, 19, 329-339.

Rogers, T. T., Lambon Ralph, M. A., Garrard, P., Bozeat, S., McClelland, J. L., Hodges, J. R. et al. (2004). The structure and deterioration of semantic memory: A neuropsychological and computational investigation. Psychological Review, 111, 205-235.

Roodenrys, S., \& Hinton, M. (2002). Sublexical or lexical effects on serial recall of nonwords. Journal of Experimental Psychology: Learning, Memory and Cognition, 28, 29-33.

Snowden, J. S., \& Neary, D. (2002). Relearning of verbal labels in semantic dementia. Neuropsychologia, 40, 1715-1728.

Snowden, J. S., Neary, D., \& Mann, D. M. A. (Eds.). (1996). Frontotemporal lobar degeneration: Frontotemporal dementia, progressive aphasia, semantic dementia. London: Churchill Livingstone.

Szmalec, A., Duyck, W., Vandierendonck, A., Mata, A. B., \& Page, M. P. A. (2009). The Hebb repetition effect as a laboratory analogue of novel word learning. The Quarterly Journal of Experimental Psychology, 62(3), 435-443.

Thorn, A. S. C., \& Frankish, C. R. (2005). Long-term knowledge effects on serial recall of nonwords are not exclusively lexical. Journal of Experimental Psychology: Learning, Memory and Cognition, 31, 729-735.

Warrington, E. K., \& James, M. (1991). The visual object and space perception battery. Bury, St. Edmunds, Suffolk: Thames Valley Test Company. 